and Survivorships was founded and, until early in the nineteenth century, this was the only company having a substantial number of lives assured on its books. The lives represent a provident type drawn from the professional and business classes, with a sprinkling of landed gentry on one hand and of clerks and servarits on the other. Three mortality experiences were quoted: Arthur Morgan's, 1762-1829; H. W. Manly's, 1863-1893 ; and a recent experience, 1924-1938. The rates of mortality were light and show a steady decrease up to about age 77 . In the most recent experience the rates of mortality are about one fourth of those of the first experience up to age 47 , and rather less than one half of those of the second experience. The proportional fall decreases at the older ages until there is little change from age 82 onwards. As regards the general population, the English Life Tables Nos. 3, 5 and 10 were used for comparison as they correspond most nearly in date to the assurance experiences. From No. 3 to No. 5 the mortality decreased by about one quarter at early adult ages and by about one tenth between ages 30 and 40 . From then onwards No. 5 shows an increase in mortality over No. 3, and even though the methods of construction and reliability differ it seems probable that mortality actually increased. From No. 5 to No. 10 there was a decrease of about one half in the rates of mortality up to age 47 , dropping to one tenth at age 77 , and showing on the whole a smaller decrease at the later ages. These changes are similar to those between the two corresponding experiences of the assurance offices, though the general population has, as would be expected, a higher mortality than that of lives assured.

\section{Control of Infectious Diseases}

IN a Chadwick Lecture given on March 16 by Dr. Robert Cruickshank, of the L.C.C. Group Laboratory, it was stated that although the mortality from infectious diseases has steadily declined in the past half-century, approximately one out of every five deaths is at present due, directly or remotely, to infection. To assess the effect of past measures and as a guide to new methods of control, the bulk of infectious diseases can best be analysed in four main groups : (1) acute respiratory infections ; (2) tuberculosis ; (3) intestinal infections; and (4) childhood fevers (whooping cough, measles, diphtheria, scarlet fever, in that order of importance). The" pneumonias and bronchitis are pre-eminent as a cause of death among the infections (they are third on the list among deaths from all causes); sulphonamides have failed to produce any striking reductions in the deathrate from these causes. A promising beginning has been made in the control of influenza, but the com. mon cold is still a major public health and economic problem.

The upward trend of tuberculosis in war-time the causes are hypothetical-has helped to accelerate measures for its better control; the role of artificial vaccination needs fresh consideration in Great Britain. Typhoid fever declined sharply coincidental with the introduction of the water-carriage system of sewage disposal, but paratyphoid, bacterial food-poisoning and bacillary dysentery are now more prevalent than they were. Their control will be closely linked with improved personal hygiene, particularly of food-handlers. The highly fatal gastroenteritis of infancy is an unsolved problem needing urgent attention. Whooping cough is the most serious of childhood infections; it can be prevented o: attenuated by prophylactic vaccination. Measles, itself a mild disease, is a menace because of its secondary complications. Diphtheria may not be wholly preventable but should cease to cause death. The means by which improvements in the control of infectious disease can be'effected are : (1) administrative regionalization (with the medical officer of health, the practitioner and the bacteriologist as co-operative partners) ; (2) structural (improved design and equipment of hospital, school and home) ; (3) educational (of child, parent, nurse, student, medical man); (4) preventive (better feeding, better hygiene, artificial immunization, new methods for the control of air-borne infections).

\section{Mild Winter of $1942-43$}

THE break in the series of severe war-time winters in Great Britain effected by the mild weather at the end of 1942 and in the early part of 1943 had an interesting effect upon the wild life of the English countryside compared with the previous three winters. Although in Scotland wildfowl and wild geese were reported to have been as numerous as in the previous season, in most parts of England the golden-өye, a characteristically abundant visitor in the previous war winters, was much less numerous. In west Cumberland in the middle of February the hatching of brown trout and sea-trout eggs was reported to be some thirty days in advance of the previous seasons, although in an article on "The Spawning Habits of Salmon" in the Field (February 6), G. M. King, clerk to the Dee Fishery Board, contends that in thirty-four years' experience he has failed to find that prevailing weather conditions affect the spawning time of these fish. In other parts of Lakeland there were many plants of red dead nettle, shepherd's purse, red campion, ivy-leaved toadflax, etc., in flower at Christmas. Over England generally the yellow winter jasmine was reported to have given one of the finest flowering displays for many years, and the songs of the song-thrush and skylark commenced several days earlier than usual. The missel-thrush was reported sitting on its nest in North Wales in February, and the song-thrush nestbuilding in Lancashire on February 6, and sitting on eggs on February 17. In Sussex and most other parts of Great Britain the exceptionally early pairing of partridge was also noted; in Cumberland these birds had paired by Christmas. Another Sussex feature was the early breeding of rabbits. From the Home Counties there were many early reports of hazel flowers, male and female, recorded in the Times in January.

\section{Recording Technique in Electro-Biology}

Av interesting paper entitled "Amplifying and Recording Technique in Electro-Biology, with Special Reference to the Electrical Activity of the Human Brain" was read by G. Parr and W. Grey Walter at a meeting of the Wireless Section of the Institution of Electrical Engineers on March 3. One of the fundamental properties of the living cell is the production of an" electromotive force, which changes when the cell is stimulated into activity. In order to study the nature and magnitude of these biological E.M.F.'s, special amplifying methods and in. put circuits are required, operating suitable visual, photographic or pen-writing recorders. The paper referred to reviews the standard methods of obtain- 
ing records, and the application of these to the recording of the potentials in the human cerebral cortex. The magnitude of the potentials produced by the brain varies from 5 to 1,000 micro-volts; it is of alternating wave form, of frequencies ranging from 1 to 20 cycles per second, and very irregular. The frequency of the output from an abnormal brain (for example, epileptics and cases of cerebral tumours) differs appreciably from that of the normal, and from this and other indications it is claimed to be possible to diagnose mental diseases and locate with considerable accuracy the sites of tumours.

Although the records in most cases show a wave form of a main predominant frequency, this is frequently interrupted by irregular groups or bursts of waves of other frequencies. These irregularities have a definite clinical significance, and it is therefore of importance to analyse the record accurately to determine the frequencies present. The authors described a tuned reed autographic analyser which has been developed for this purpose, and showed an example of its application. The reading of the paper was accompanied by a demonstration on a human subject, in which the varying effects of permitting the brain to rest and of stimulating it into activity were shown by records on a cathode ray oscillograph.

\section{Golden Gate Bridge}

INSTRUMENTS have recently been installed on the Golden Gate Bridge at San Francisco for accurate recording of movements that occur under wind loads (Earthquake Notes, 14, Nos. 1 and 2; 1942). These include a wind velocity recorder, a wind directional recorder and a non-sensitive recording seismograph. Vertical and horizontal graduated boards at midspan will facilitate observations with a transit to measure movement in these two planes. The wind vane and anemometer are mounted on a structural steel platform on the west or ocean side of the bridge at midspan. Both these instruments are electrically connected to motor-driven recording units in the east leg of the south tower. At this point a 24-hour continuous record is maintained from the two wind instruments and the seismograph. With these records it is expected that useful information will be obtained as to the various movements caused under different wind conditions; for example, as in the case of a $72 \mathrm{~m} . \mathrm{p} . \mathrm{h}$. wind such as was recorded during a storm in 1938.

\section{Earthquakes Registered in New Zealand}

DuRING November 1942 ten earthquakes were registered by the seismographs at Auckland, Arapuni, Christchurch, Kaimata, New Plymouth, Tuai and Wellington, according to a seismological report just received (Prov. Bull. No. P-129, November 1942, Dominion Observatory, Wellington W.1, New Zealand). The greatest was on November 10 when the trace amplitude on the $Z$ record was $12 \mathrm{~mm}$. This earthquake began recording with $P$ compression at 11h. 53m. 45s. U.T. from an epicentral distance of $82^{\circ}$ and from an azimuth south-south-west of Christchurch. The shock of November 3 had a focal depth of $350 \mathrm{~km}$., and the next deepest focus occurred on November 7 (180-200 km.). The most intense of the twenty-six earthquakes felt during the month in New Zealand had intensity 5 on the Rossi-Forel scale. This occurred on November 26 at $1 \mathrm{~h}$. $31 \cdot 6 \mathrm{~m}$. U.T. from an epicentre near latitude $41^{\circ} \mathrm{S}$., longitude
$172 \cdot 3^{\circ} \mathrm{E}$. Masterton was most often affected during the month, and Wellington experienced three small shocks on November 3, 7, and 14 .

\section{Activity on Jupiter's South Equatorial Belt}

Mr. B. M. PEEK, director of the Jupiter Section, British Astronomical Association, reports a remarkable outbreak of activity in Jupiter's South Equatorial Belt. This outbreak commenced at some time between February 7 and 11 in System ii longitude $15^{\circ}$ approximately. It is possible that there will be a repetition of the phenomena of 1928-29. The preceding end of the disturbance is advancing rapidly along the north component of the belt in the direction of decreasing System ii longitude : the main features, however, are not rotating so rapidly as System i. In the following portion there are some dark humps on the south component of the belt, the System ii longitude of which is increasing rapidly. Assuming that the rate of drift is maintained, the first of these humps-which is more like a streak than a humpshould reach conjunction with the preceding end of the Red Spot in the first week in April. One important difference between the present outbreak and that of 1928-29 is the appearance of a second centre of disturbance on March 1 about longitude $290^{\circ}$, System ii. Mr. Peek conjectures that the preceding end of the whole disturbed region may soon pass to the north of the Red Spot. If this should occur, it would cause the Red Spot Hollow, which has recently been very faint, to grow darker again.

\section{Variation in $\delta$ Ursæ Majoris}

A BRIEF notice about the variation in the brightness of this star appeared in NATURE of February 6 , p. 165. Additional corroborative evidence is afforded by further observations by Mr. N. F. Knight in North Africa, and Mr. F. M. Holborn at Streatham, London. Mr. Knight's latest observation, made on February 2, gives the magnitude $3 \cdot 5-3 \cdot 6$, and $\mathrm{Mr}$. Holborn had recorded the same magnitude on February 2. Mr. Holborn's most recent observations on February 26 and March 4 show that the star is now practically back to its normal magnitude, $3 \cdot 4$. It may be recalled that $\mathrm{Mr}$. Knight estimated its magnitude as $3 \cdot 8-3 \cdot 9$ on December 10 , and on January 14 and 15 , Mr. Holborn's estimate was $3 \cdot 7$.

\section{Announcements}

Dr. H. Spencer Jones, Astronomer Royal, has been awarded the Gold Medal of the Royal Astronomical Society for his determination of the solar parallax.

Sir BennetT Melvill Jones, professor of aeronautics in the University of Cambridge, has been appointed chairman of the Aeronautical Research Committee in succession to Sir Henry Tizard.

THE University of Sheffield has received a gift of $£ 800$ from an anonymous donor to provide equipment for the Department of Geology after the War.

Mr. A. Wright has resigned from his post of lecturer in mining, on his appointment as senior investigator to the Lancashire and Cheshire Safety in Mines Research Committee.

The Director of the Seismological Institute of the University of Chile reports that a new seismograph consisting of both horizontal and vertical components is being installed at the University in Santiago, Chile. 